\title{
Ways to Improve the Productivity of Oasis Agriculture: Increasing the Scale of Household Production and Human Capital? A Case Study on Seed Maize Production in Northwest China
}

\author{
Yao Wei ${ }^{1}$, Fanglei Zhong ${ }^{2, *}{ }^{\mathbb{D}}$, Xijing Luo ${ }^{2}$, Penglong Wang ${ }^{3}$ and Xiaoyu Song ${ }^{3, *}$ \\ 1 School of Economics, Lanzhou University, Lanzhou 730000, China; ywei2020@lzu.edu.cn \\ 2 School of Economics, Minzu University of China, Beijing 100081, China; luoxj@bjast.ac.cn \\ 3 Northwest Institute of Eco-Environment and Resources, Chinese Academy of Sciences, \\ Lanzhou 730000, China; wangpl@llas.ac.cn \\ * Correspondence: zfl@muc.edu.cn (F.Z.); songxy@llas.ac.cn (X.S.)
}

Citation: Wei, Y.; Zhong, F.; Luo, X.; Wang, P.; Song, X. Ways to Improve the Productivity of Oasis Agriculture: Increasing the Scale of Household Production and Human Capital? A Case Study on Seed Maize

Production in Northwest China. Agriculture 2021, 11, 1218. https:// doi.org/10.3390/agriculture11121218

Academic Editors: Vítor João Pereira Domingues Martinho, Paulo Reis Mourão and Nikolaos Georgantzis

Received: 10 November 2021

Accepted: 30 November 2021

Published: 2 December 2021

Publisher's Note: MDPI stays neutral with regard to jurisdictional claims in published maps and institutional affiliations.

Copyright: (c) 2021 by the authors. Licensee MDPI, Basel, Switzerland. This article is an open access article distributed under the terms and conditions of the Creative Commons Attribution (CC BY) license (https:// creativecommons.org/licenses/by/ $4.0 /)$.

\begin{abstract}
Oasis agriculture in arid areas faces the constraints of scarce resources and a fragile ecological environment. Improving agricultural production efficiency is the key solution. However, there are few studies analyzing the relationship between farmers' production efficiency and planting scale from a micro-empirical perspective. Herein, we study the seed-producing corn growers in Zhangye city, and supplement special survey data with national input-output survey data. We use data envelopment analysis to measure agricultural production efficiency, and tobit regression to calculate the marginal effects of factors affecting production efficiency on farms of different scales. The results show that production efficiency is greater for large-scale farmers than for small-scale farmers. Duration of technical training, education time of laborers, planting income, and productive expenditure are significantly positively correlated with production efficiency. Average age of farmers and the amount of pesticide and fertilizer use are significantly negatively correlated with production efficiency. Off-farm activities improve the production efficiency of small-scale farmers but inhibit it for medium- and large-scale farmers. Differences exist in marginal impacts for different scales of farmland. We conclude that expanding the scale of family farms and optimizing human capital are effective for improving agricultural production efficiency in arid oasis areas.
\end{abstract}

Keywords: arid oasis agriculture; production efficiency; household farmland; human capital

\section{Introduction}

Arid and semi-arid regions account for 58.74\% of China's land area, and arid land agriculture is an important part of its agriculture, maintaining the livelihoods of about 7.84 million people [1]. Oasis agriculture is the essence of agriculture in the arid regions of northwest China, which are mostly concentrated in Gansu, Ningxia, Qinghai, Shaanxi, and Xinjiang. Owing to the dual constraints of scarce natural resources and a fragile ecological environment, the development of oasis agriculture lags behind the national average level of agriculture. One of China's key characteristics is a large and growing population but limited land, resulting in a land fragmentation problem. As a result, the main players in agricultural production in the northwest arid region are small-scale farmers at present. How to promote cooperation and alliances among small farmers, how to encourage organic connections to develop a modern agricultural, and how to enhance overall food production capacity have become urgent problems requiring resolution. At the same time, with the growth of nonagricultural employment and the selective transfer of the rural labor force, the agricultural labor force in the northwest region is continuously decreasing and demonstrating an aging trend. The loss of rural human capital will inevitably have a significant impact on the development of the agricultural economy. Assessing the 
efficiency of agricultural production in oasis areas and exploring ways to improve efficiency is essential to overcoming these dual restrictions. Greater efficiency can surmount the constraints of water shortages and environmental degradation of oases in arid regions, and contribute to achieving sustainable agricultural production and regional food security and stability. However, whether expanding the scale of household farmland and optimizing human capital is an effective means of improving agricultural production efficiency in arid oasis areas requires further research.

Most studies in the existing literature use macro-level data in researching agricultural production efficiency [2-7]. There are few studies that focus on micro-farmers, concentrate on analyzing the relationship and mechanisms between various influencing factors systematically, and study the production efficiency of farmer households of different scales from an empirical perspective. Farmers are the most basic decision-making behavioral unit in agricultural production. Evaluating production efficiency and analyzing its influencing factors from the perspective of micro-farmers' input and output levels will undoubtedly have strong pertinence and practical significance.

This article supplements special survey data with national input-output data, focusing on micro-farmers as the main research object. We use the data envelopment analysis (DEA) method to measure the micro-farmers' agricultural production efficiency values, and a tobit regression to calculate the marginal effects of factors affecting production efficiency. From an empirical perspective, this paper systematically analyzes the relationship between each influencing factor and the production efficiency of farmers operating at different scales. Particular attention is paid to the impact of human capital on the agricultural production efficiency of different scales of farmland. Finally, we put forward recommendations to promote the improvement of agricultural production efficiency in arid oasis areas.

The following text is arranged as follows: the theoretical background and literature review section summarizes the previous studies and relevant theories in detail. The Materials and Methods section describes the methods, data sources, and indicators used in this study. The Results section fully demonstrates and discusses the empirical results. The Discussion section explains in detail the logic and reasons behind the empirical results. In the final Conclusion section, specific recommendations for the development of oasis agriculture in arid regions of China are presented in the context of the study results.

\section{Theoretical Background and Literature Overview}

Agricultural production efficiency concerns the degree of utilization of agricultural resources in the process of agricultural production. It refers to the ratio between agricultural inputs and outputs given the context of environmental conditions and current policies $[8,9]$. Agricultural production efficiency reflects the comprehensive agricultural production capacity, which is based on agricultural resource endowments, the degree to which science and technology are applied to agricultural production, the quality or human capital of agricultural laborers, and the management and control of the production process $[10,11]$.

\subsection{Measuring Agricultural Production Efficiency}

Owing to differences in geographical environments, in general, international scholars have largely focused on agricultural production efficiency on farms, whereas Chinese scholars have analyzed agricultural production efficiency in different years and at the province, city, and even county levels. The main research methods used to examine agricultural production efficiency are the parametric and nonparametric methods. Parametric methods can be further divided into deterministic and stochastic methods. The deterministic method uses data based on frontiers and feasible technologies, and regards the distance between the observed production and the maximum possible production as technical inefficiency, whereas the stochastic method allows for a difference between technical efficiency and statistical noise. Parametric methods require the establishment of a specific production function to determine production efficiency. In contrast, nonparametric methods do not require specific functional forms to describe efficiency frontiers or envelopes. The adaptability 
of nonparametric techniques allows for alternative concise forms. Currently, nonparametric DEA is the most frequently used method for the analysis of production efficiency [12].

Other studies using parametric methods to measure production efficiency include that of Onukand et al., who used stochastic frontier functions to estimate the technical relationship between input and output in corn production, and determined the technical efficiency of corn farms in the southern agricultural area of Nasarawa state, Nigeria [13]. Huang et al. selected panel data from 31 provinces (cities) in China from 2007 to 2017, and used a stochastic frontier analysis model to measure the efficiency of China's agricultural production technology and its influencing factors [14]. Jittima et al. studied the agricultural production efficiency of Cambodia, Laos, Myanmar, and Vietnam by using the Bayesian stochastic frontier analysis method [15]. Research on the use of nonparametric methods to measure production efficiency includes Salame, who examined the agricultural productivity of Israel, Jordan, Lebanon, and Syria during the period from 1972 to 2006 under the influence of war, using the DEA method to study the agricultural productivity trends [16]. Asmat Ullah et al. combined the life-cycle assessment method with the DEA method, taking into account all resource consumption and environmental pollution in the agricultural production process, and evaluated local agricultural production efficiency [17]. Mita Bagchi et al. used the bootstrapped DEA method to study the growth of agricultural productivity and its components in Bangladesh from 1987 to 2009 [18].

The agricultural production to which the parametric method can be applied involves multiple inputs corresponding to a single output, where there is a linear relationship between inputs and output. The calculation process for the parametric method is complex and the scope of application is narrow, which has certain limitations. The nonparametric method uses the DEA model to explore the influencing factors of production efficiency, and enables improvement of the overall agricultural production efficiency by examining the impact of various indicators on production efficiency. Its greater flexibility can produce a better representation of the level and distribution of technical efficiency.

\subsection{Factors Affecting Agricultural Production Efficiency}

Scholars in China and internationally have conducted in-depth researches on the factors influencing agricultural production efficiency. By reviewing relevant research documents, we have analyzed and summarized the influencing factors, with a focus on the technical level, the scale of farming households, the investment of human resources, and the elements of agricultural machinery and agricultural structure. We briefly outline the studies in relation to various influencing factors below.

1. Production technology. Theodoridis used the DEA model to study the production efficiency of Greek farms, and found that they suffered from low resource allocation efficiency and that technology was a key factor in improving their efficiency [19]. Liu et al. used the environmental policy integrated climate (EPIC) model to calibrate and evaluate the wheat high-yield experiment in Hebei Province, and estimated wheat output at the county level. The results showed that China should invest in the transfer of irrigated wheat production technology [20]. Abdul-Rahaman Awal et al. investigated the impact of improved rice technology on the productivity and efficiency of 412 smallholder rice farmers in northern Ghana, and found that the technical efficiency of adopters was $24 \%$ higher than that of nonadopters [21].

2. Planting scale of farmers. Chandra conducted a comparative analysis on the agricultural production efficiency of different farm scales in Nepal, and found that farms too large or too small are not conducive to the realization of maximum agricultural production efficiency [22]. Ángeles et al. examined the production efficiency of small family farms as the main decision-making unit of horticulture in southeastern Spain from a micro level [23]. Stepień Sebastian et al. assessed the ecological efficiency of small-scale farms in Poland, and studied the relationship between ecological efficiency and institutional variables in accordance with a new institutional economics 
framework. They found that the most ecologically efficient farms are those with relatively large areas [24].

3. Human resources investment. Baba et al. analyzed the impact of human resources on agricultural productivity in rural areas of Jammu and Kashmir. Research shows that human resources play an important role in determining agricultural productivity [25]. Bazyli et al. established a structural equation model using 674 small farms in Poland as a sample. The analysis confirmed that human capital and agricultural production have a strong correlation, and that training plays a vital role in this relationship [26].

4. Inputs of agricultural machinery. Yin et al. examined Chinese maize, rice, and wheat production and found that the current nitrogen fertilizer application rate has resulted in high social costs in the process of achieving high yields and economic benefits. In addition, they calculated the socially optimal nitrogen application rate to maximize crop productivity and agricultural income [27]. Xie et al. conducted a comprehensive analysis of data sets from agricultural surveys and previously published studies in a typical high-nitrogen input region in China. Studies have shown that centralized management, good agronomy, and advances in knowledge and technology are essential for future agricultural development [28]. PangapangaPhiri Innocent et al. studied the reasons why drought-affected farmers' adoption of climate-saving agricultural practices and their impact on the efficiency of corn production technology. They found that the simultaneous application of organic fertilizer and inorganic fertilizer on the same farm significantly increased the technical efficiency of corn production by $18 \%$, and even more significantly among droughtaffected farmers [29].

5. Agricultural structure. Manjunatha et al. analyzed the impact of factors such as farm size and crop diversity on the profit and efficiency of 90 groundwater irrigation farms in the hard rock region of southern India. They found that crop diversity is negatively and significantly correlated with low efficiency, and that the average profits and efficiency of farms with diversified planting patterns are higher than those of similar farms [30]. Zeng et al. applied quantile regression to analyze the impact of crop diversity on agricultural production, nonpoint source pollution, and agricultural ecological efficiency in China. Their results indicated that crop diversity had a negative impact on agricultural output and nonpoint source pollution, and a positive impact on the national agricultural eco-efficiency [31]. Senthold Asseng et al. showed that vertical planting is a possible and promising option to increase wheat production in the future [32]. Subhash Babu et al. showed that the use of corn fallow and improved food security in the eastern Himalayas may contribute to the sustainable development of agriculture and the realization of a circular economy model in the agricultural sector [33].

6. Other factors. (a) Worker behavior. Pham Huong-Giang et al. found that the knowledge transfer and peer learning of the production workers had a significant impact on agricultural productivity, and suggested strengthening the cooperation between extension agencies, farmer groups, and peers [34]. (b) Type of agricultural system. Rusciano et al. conducted a questionnaire survey of 150 farmers in two different areas of Naples to analyze the relationship between the urban garden patterns and the sustainability of the environment [35]. David Berre et al. compared the results of the specific frontier of the agricultural system with the surrounding meta-frontier and found that the gap between efficiency and benefit was overestimated in the meta-frontier method by $13 \%$ [36].

Scholars have used different analytical methods to measure the production efficiency of different regions and different crops, and have studied the influencing factors of the production efficiency. These studies on agricultural production efficiency have laid an important foundation for further research, but certain limitations remain. (1) Researches have largely focused at the national and inter-provincial scale or on broad geographical administrative divisions, and there is little analysis of the main crops in specific more 
localized areas. (2) Researchers largely use macro-level data, and few studies combine macro-statistical data and micro-field surveys. (3) The existing studies focus on the effects of different factors influencing agricultural production efficiency, but little attention has been paid to the comprehensive effects of such different factors on agricultural production efficiency.

In this paper, we take the corn planters in Zhangye City, a typical agricultural area in the arid area of northwest China, as an example. We supplement special survey data using national input-output data, focus on micro-farmers, and use the DEA method to calculate the agricultural production efficiency value. We use a tobit regression to further calculate the marginal effect of the factors influencing production efficiency. From an empirical perspective, our paper systematically analyzes the relationship and mode of action between various influencing factors and the production efficiency of farmers of different scales, with special attention given to the impact of human capital on the agricultural production efficiency of farmland of different scales.

\section{Materials and Methods}

\subsection{Methods}

\subsubsection{Data Envelopment Analysis}

The data envelopment analysis method, also known as DEA method, was proposed by American operations researchers A. Charnes and W.W. Cooper in 1978 [37]. It is a relative efficiency evaluation method based on linear programming theory, which is used to evaluate the efficiency of the same type of organization with multiple input systems and multiple output systems. The advantage of DEA is that it does not need to determine the production function in advance, and it is not affected by the dimensions of input and output data [38]. The most representative DEA models are the CCR model with constant returns to scale and the BCC model with variable returns to scale [39]. According to the different focuses of researchers, the DEA model can be further divided into input-oriented and output-oriented. The former focuses on the input minimization when the output is given, while the latter focuses on the output maximization when the input is given [40].

This article aims to analyze the agricultural production efficiency of farmers of different scales, and the research object has the characteristic of variable returns to scale. We set the annual yield of crops as the output unit and various productive inputs as inputs in this paper. Compared with the output of crops, production inputs are more artificially controllable. The purpose of this study is to enable farmers to achieve the best efficiency while reducing the input of available elements as much as possible. Therefore, we use the input-oriented BCC model with variable returns to scale to measure the production efficiency of farmers. We divide technical efficiency into two categories, pure technical efficiency and scale efficiency, for the analysis [41]. The improved input-oriented BCC model according to research needs is as follows:

$$
\begin{gathered}
\min \theta-\varepsilon\left(\hat{\mathrm{e}}^{T} S^{-}+e^{T} S^{+}\right) \\
\text {st. }\left\{\begin{array}{c}
\sum_{j=1}^{n} X_{j} \lambda_{j}+S^{-}=\theta X_{0} \\
\sum_{j=1}^{n} Y_{j} \lambda_{j}-S^{+}=Y_{0} \\
\lambda_{j} \geq 0, S^{-}, S^{+} \geq 0 \\
\sum_{j=1}^{n} \lambda_{j}=1
\end{array}\right.
\end{gathered}
$$

where $X$ and $Y$ are the input and output vectors, respectively, $\theta$ represents the comprehensive technical efficiency of the decision-making unit, $e=(1,1, \ldots, 1)^{T} \in E^{m}$, $\hat{\mathrm{e}}=(1,1, \ldots, 1)^{T} \in E^{s}, S^{+} \in E^{m}, S^{-} \in E^{s}, \varepsilon$ is the non-Archimedean infinitesimal quantity, $\lambda_{j}(j=1,2, \ldots, n)$ is the weight vector of the inputs and output of each decision-making unit, 
and $S$ is the slack variable. If $\theta=1$ and $S^{+}=S^{-}=0$, the DEA of the decision-making unit is valid, whereas if $\theta<1$, the decision-making unit is not valid.

\subsubsection{Tobit Regression}

In 1958, the tobit model was proposed by the American scholar Tobin [42]. It is a value model used when the continuous explained variable is subject to certain restrictions. Tobit model is also called the restricted dependent variable model and the sample selection model. In this study, the agricultural production efficiency measured by the DEA method will be used as the explained variable, and its influencing factors will be used as the explanatory variables to establish a multiple regression model. The efficiency value measured by the DEA method has a range of $(0,1)$, which are truncated data. Compared with other multiple regression models, the tobit model is more suitable for situations where the value of the dependent variable is limited [43]. The model settings are as follows [44]:

$$
\begin{gathered}
y_{i}^{*}=X_{i} \beta+u_{i} \\
u_{i} \sim N\left(0, \sigma^{2}\right) \\
y_{i}= \begin{cases}y_{i}^{*}, & \text { if } y_{i}^{*}>0 \\
0, & \text { if } y_{i}^{*} \leq 0\end{cases}
\end{gathered}
$$

where $y_{i}^{*}$ is a potential explained variable and satisfies the basic assumptions of the classic linear model. $y_{i}$ is an explained variable and it represents the production efficiency value of the farmer in this paper. $X_{i}$ is a vector of explanatory variables used to represent the factors influencing the farmer's production efficiency. $\beta$ is the coefficient to be estimated, and $u_{i}$ is the residual item that is independent and obeys a normal distribution $N\left(0, \sigma^{2}\right)$.

\subsection{Data Collection and Selection of Indicators}

\subsubsection{Data Collection}

Zhangye City is located in the northwest of Gansu Province, in the middle of the Hexi Corridor, where the Qinghai-Tibet and Mongolian Plateaus meet. It is located on two national nature reserves, Qilian Mountain and Heihe Wetland. Zhangye has sparse rainfall, a dry climate, and sufficient sunshine all year round. It has a typical temperate continental arid climate. As a characteristic desert oasis area, with numerous rivers, fertile land, and convenient irrigation, Zhangye is a national modern agricultural demonstration area, the country's largest corn seed production area and an important grain production base. It is also an area representing classic oasis agriculture in arid regions. In 2020, Zhangye's hybrid corn seed production area reached 63,753 hectares, with an increase of 3747 hectares compared to last year, and a growth rate of $6.24 \%$. Zhangye's planting area for seed maize accounts for $41.5 \%$ of the national hybrid maize production area [45]. As a national-level hybrid corn seed production base, the Zhangye seed maize industry is now the most industrialized agricultural industry in the area, and seed maize production has become an important source of income for local farmers. However, the overall local corn production method is relatively extensive, with long-term decentralized operations being the main method used. The efficiency of agricultural production has always been restricted by the scarcity of resources and the fragile ecological environment, which is not conducive to the long-term sustainable development of agriculture.

The data in this article are derived from the special survey, supplemented by the national input-output survey. The research object of the special survey is the seed-producing corn farmers in Zhangye City. The study area and the distribution of sampling points are shown in Figure 1. The survey uses a combination of stratified random sampling and typical sample selection to select sample points. In November 2020, we conducted household interviews and a questionnaire survey with 176 seed-producing corn growers in various townships in Zhangye City, and a comprehensive survey of their annual seed-producing corn planting situation. The study used random and purposive sampling designs to collect both quantitative and qualitative data. During the field investigation, the 
purposive sampling was used to select the representative villages in the study area, key informants, and members of focus group discussions. We selected a focus group approach to capitalize on interactive discussions with several different categories of farmers. This approach involved conversational sessions, making the interviewees more relaxed and willing to participate. After excluding incomplete data questionnaires, a total of 135 valid questionnaires were obtained, representing an effective response rate of $76.7 \%$.

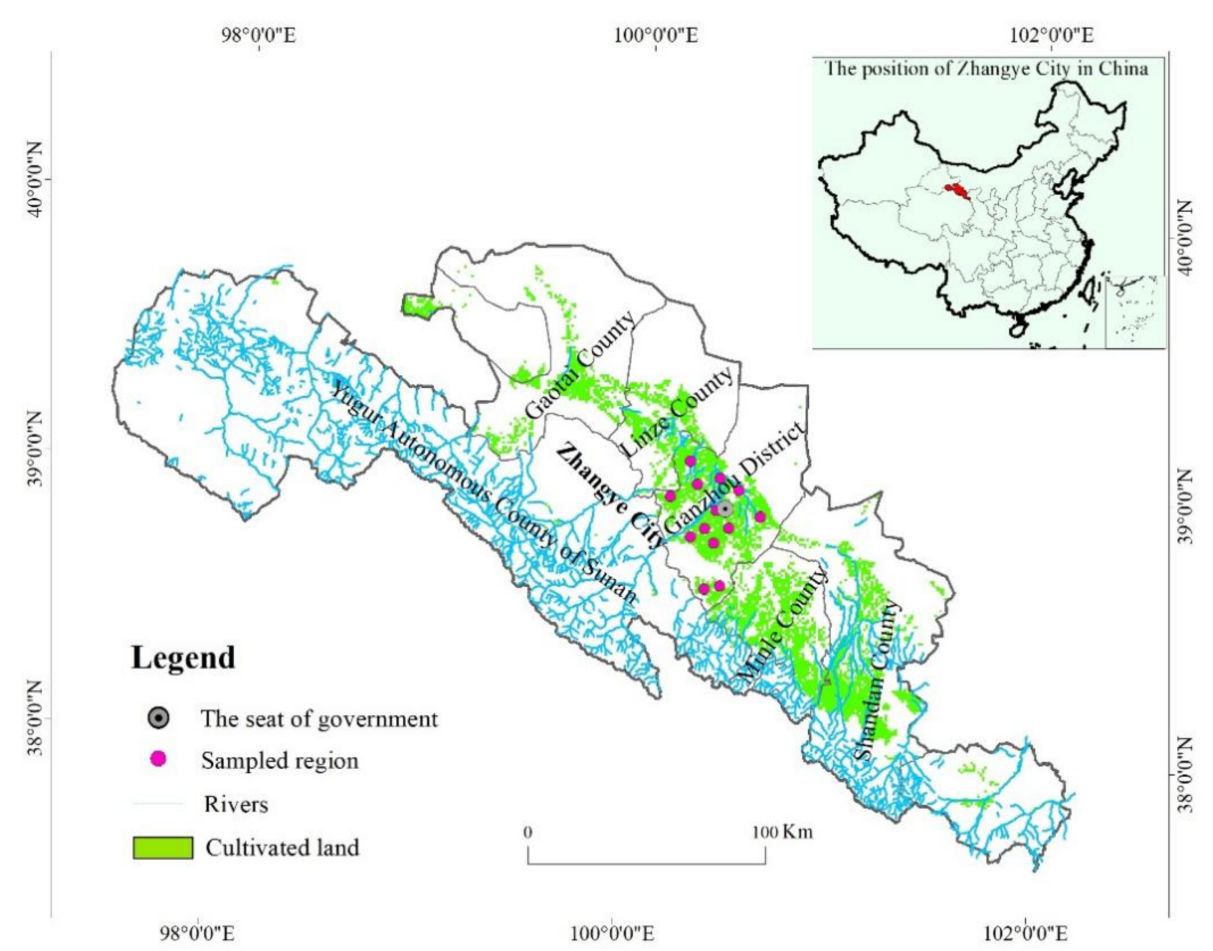

Figure 1. Overview of the study area and distribution of sampling points.

\subsubsection{Selection of Indicators and Data Description}

Based on the existing studies [46-51] and investigation of the actual situation of farmers planting corn for seed production, we divide the production inputs into five components: labor, environmental, irrigation, machinery, and land inputs. We select eight input indicators: labor force, seed purchases, pesticide purchases, agricultural film purchases, fertilizer use, irrigation water fees, mechanical power costs, and corn planting area. The main output indicator is the annual corn output. The relevant index data involving prices are all in 2020 values, so there is no need to deflate the price index. The selection and description of input-output indicators are shown in Table 1.

The statistical description of the sample population is shown in Table 2. For labor inputs, the sample standard deviation is 0.96 . The difference in the number of laborers planting corn among rural households in each township is small, and the average labor input is 2.63 , indicating that corn-planting farmers still conduct decentralized operations with households as their main unit. The average planting area of seed-producing corn is 0.92 hectare, the scale of production is not high, and the planting scale varies greatly among towns. The remaining input factors and output indicators vary greatly among different farmers. 
Table 1. Index selection and units for the input-output efficiency evaluation.

\begin{tabular}{|c|c|c|c|}
\hline \multicolumn{3}{|c|}{ Index } & Index Description \\
\hline \multirow{8}{*}{$\begin{array}{l}\text { Input } \\
\text { indicators }\end{array}$} & Labor input & $\begin{array}{l}\text { Number of labor } \\
\text { force/person }\end{array}$ & $\begin{array}{l}\text { Number of adult laborers } \\
\text { involved in corn planting }\end{array}$ \\
\hline & \multirow{4}{*}{$\begin{array}{l}\text { Environmental } \\
\text { input }\end{array}$} & $\begin{array}{l}\text { Seed purchase } \\
\text { amount/yuan }\end{array}$ & $\begin{array}{l}\text { Expenditure on purchasing } \\
\text { corn seeds throughout the } \\
\text { year }\end{array}$ \\
\hline & & $\begin{array}{l}\text { Pesticide purchase } \\
\text { amount/yuan }\end{array}$ & $\begin{array}{l}\text { Expenditure on purchasing } \\
\text { pesticides throughout the } \\
\text { year used for corn } \\
\text { production }\end{array}$ \\
\hline & & $\begin{array}{l}\text { Agricultural film } \\
\text { purchases/yuan }\end{array}$ & $\begin{array}{l}\text { Annual expenditure on } \\
\text { purchasing agricultural film } \\
\text { used for corn production }\end{array}$ \\
\hline & & Fertilizer consumption/kg & $\begin{array}{l}\text { Annual corn planting total } \\
\text { fertilizer application used for } \\
\text { corn production }\end{array}$ \\
\hline & Irrigation input & Irrigation water fee/yuan & $\begin{array}{c}\text { Total annual irrigation water } \\
\text { expenditure }\end{array}$ \\
\hline & $\begin{array}{l}\text { Machinery } \\
\text { input }\end{array}$ & $\begin{array}{l}\text { Mechanical power } \\
\text { cost/yuan }\end{array}$ & $\begin{array}{l}\text { Annual production, } \\
\text { transportation, and } \\
\text { machinery operating } \\
\text { expenses }\end{array}$ \\
\hline & Land input & Corn planting area/hectare & $\begin{array}{l}\text { Cultivated land area for } \\
\text { growing corn }\end{array}$ \\
\hline $\begin{array}{l}\text { Output } \\
\text { indicators }\end{array}$ & & $\begin{array}{l}\text { Annual corn } \\
\text { production } / \mathrm{kg}\end{array}$ & $\begin{array}{l}\text { The yield of seed-producing } \\
\text { corn in the year (2020) }\end{array}$ \\
\hline
\end{tabular}

Table 2. Statistical description of inputs and outputs for seed corn production.

\begin{tabular}{ccccc}
\hline & Mean & Max & Min & Standard Deviation \\
\hline Number of labor force/person & 2.63 & 6.00 & 1.00 & 0.96 \\
Seed purchase amount/yuan & 954.08 & $15,000.00$ & 50.00 & 1586.74 \\
Pesticide purchase & 573.11 & 6750.00 & 20.00 & 829.84 \\
$\quad$ amount/yuan & & & & \\
Agricultural film & 573.02 & 9600.00 & 30.00 & 1065.26 \\
purchases/yuan & 1240.53 & $12,000.00$ & 60.00 & 1614.83 \\
Fertilizer consumption/kg & 1525.53 & $15,000.00$ & 75.00 & 1849.53 \\
Irrigation water fee/yuan & 2379.01 & $20,000.00$ & 0.00 & 3920.92 \\
Mechanical power cost/yuan & 0.92 & 10.00 & 0.07 & 19.87 \\
Corn planting area/hectare & $10,212.35$ & $120,000.00$ & 600.00 & $14,786.95$ \\
Annual corn production/kg & & &
\end{tabular}

\section{Results}

\subsection{Farmers' Production Efficiency According to the DEA Method}

Based on the above data, we use the maxDEA8 Basic software to calculate the production efficiency values of 135 seed-producing corn farmers in Zhangye City. Previous studies have shown that the scale of farmers' planting has a certain impact on production efficiency [52-56]. In order to explore the impact of the corn planting scale of farmers on their agricultural production efficiency, we draw a graph of the relationship between farmer's production efficiency and planting scale. The actual data exclude extreme values in analysis. Technical efficiency (TE), pure technical efficiency (PTE), and scale efficiency (SE) all show certain differences in response to changes in farmers' planting scale, as shown in Figure 2. On the whole, compared with medium-scale farmers, small-scale farmers 
and large-scale farmers have higher efficiency values. When using a polynomial for trend fitting, we find that the comprehensive technical efficiency value presents a U-shaped curve as the planting scale increases.

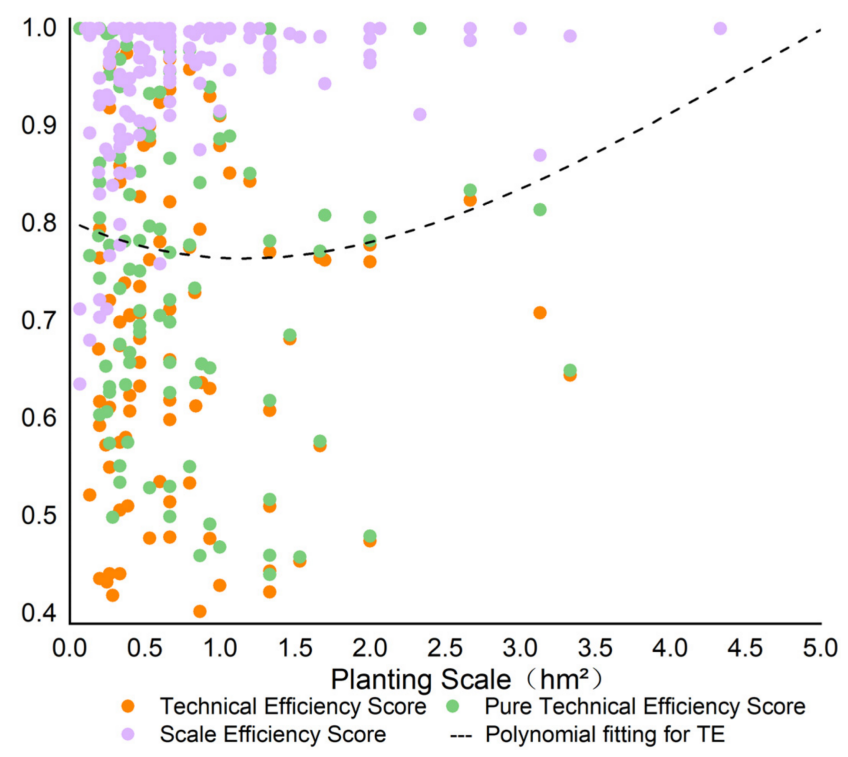

Figure 2. Relationship between technical, pure technical, and scale efficiency and the planting scale.

Based on the actual planting scale distribution of the surveyed households, we divide the sample into small-scale planting households ( $0-0.6$ hectare), medium-scale planting households (0.6-1.67 hectares), and large-scale planting households (1.67-10 hectares). According to the grouping of farmers of different sizes, we separately counted the number of farm households in the full sample and each group, as well as the number of farm households with the best efficiency. The analysis of farming households shows that, as illustrated in Figure 3, there are significant differences in the number of farms that achieve the best technical efficiency ( $\mathrm{TE}=1)$ at different planting scales. In the whole sample, $27.41 \%$ of farmers achieve the best technical efficiency. Among small, medium, and largescale farmers, those with the best technical efficiency account for $25 \%, 26 \%$, and $41.18 \%$, respectively.

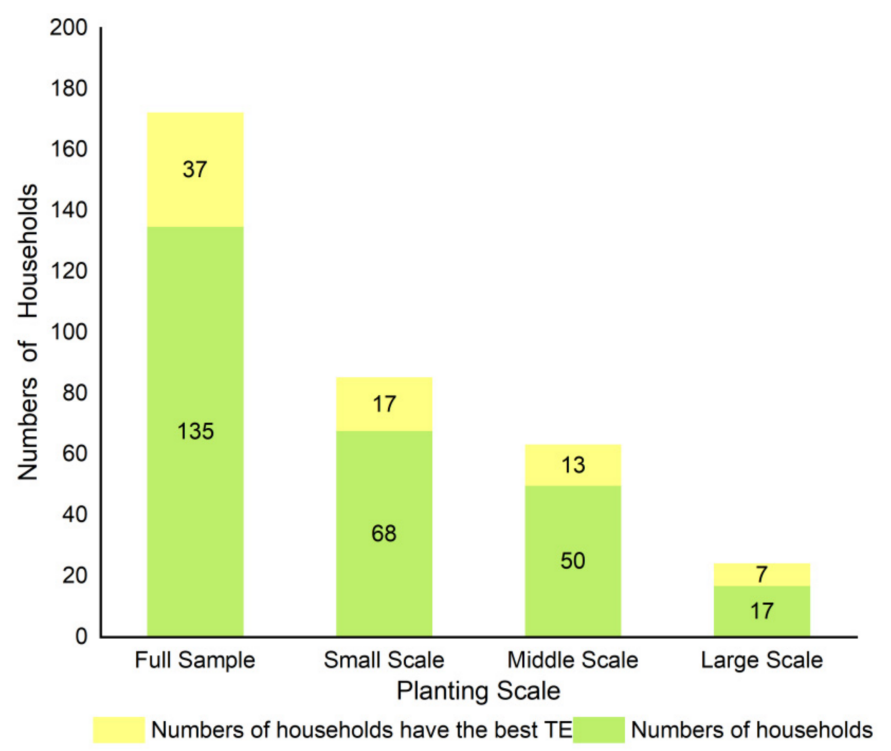

Figure 3. The number of sample farm households of different scales and farm households with the best technical efficiency. 
The statistical descriptions based on the production efficiency values of farms of different scales are shown in Table 3. As shown in Figure 4, in order to observe the production efficiency values of farmers of different scales more vividly and intuitively, we used Stata software to visualize the results in Table 3. With the planting scale increasing, both TE and PE show a downward trend and then an upward trend, while SE increases with the expansion of farming scale.

Table 3. Production efficiency values of farmer households based on different farming scales.

\begin{tabular}{|c|c|c|c|c|c|c|c|c|}
\hline & \multicolumn{2}{|c|}{$\begin{array}{c}\text { Full Sample: } \\
\quad 0-10\end{array}$} & \multicolumn{2}{|c|}{$\begin{array}{c}\text { Small Scale: } \\
0-0.6\end{array}$} & \multicolumn{2}{|c|}{$\begin{array}{c}\text { Medium Scale: } \\
0.6-1.67\end{array}$} & \multicolumn{2}{|c|}{$\begin{array}{c}\text { Large Scale: } \\
1.67-10\end{array}$} \\
\hline Average planting scale/hectare & \multicolumn{2}{|c|}{0.9193} & \multicolumn{2}{|c|}{0.3155} & \multicolumn{2}{|c|}{0.9217} & \multicolumn{2}{|c|}{3.3275} \\
\hline Efficiency value & Mean & $\begin{array}{l}\text { Standard } \\
\text { deviation }\end{array}$ & Mean & $\begin{array}{l}\text { Standard } \\
\text { deviation }\end{array}$ & Mean & $\begin{array}{l}\text { Standard } \\
\text { deviation }\end{array}$ & Mean & $\begin{array}{l}\text { Standard } \\
\text { deviation }\end{array}$ \\
\hline Technical efficiency (TE) & 0.7842 & 0.1944 & 0.7815 & 0.1916 & 0.7705 & 0.2043 & 0.8355 & 0.1656 \\
\hline Pure technical efficiency (PTE) & 0.8250 & 0.1769 & 0.8444 & 0.1615 & 0.7886 & 0.1948 & 0.8544 & 0.1622 \\
\hline Scale efficiency (SE) & 0.9460 & 0.0758 & 0.9184 & 0.0914 & 0.9729 & 0.0406 & 0.9773 & 0.0356 \\
\hline
\end{tabular}

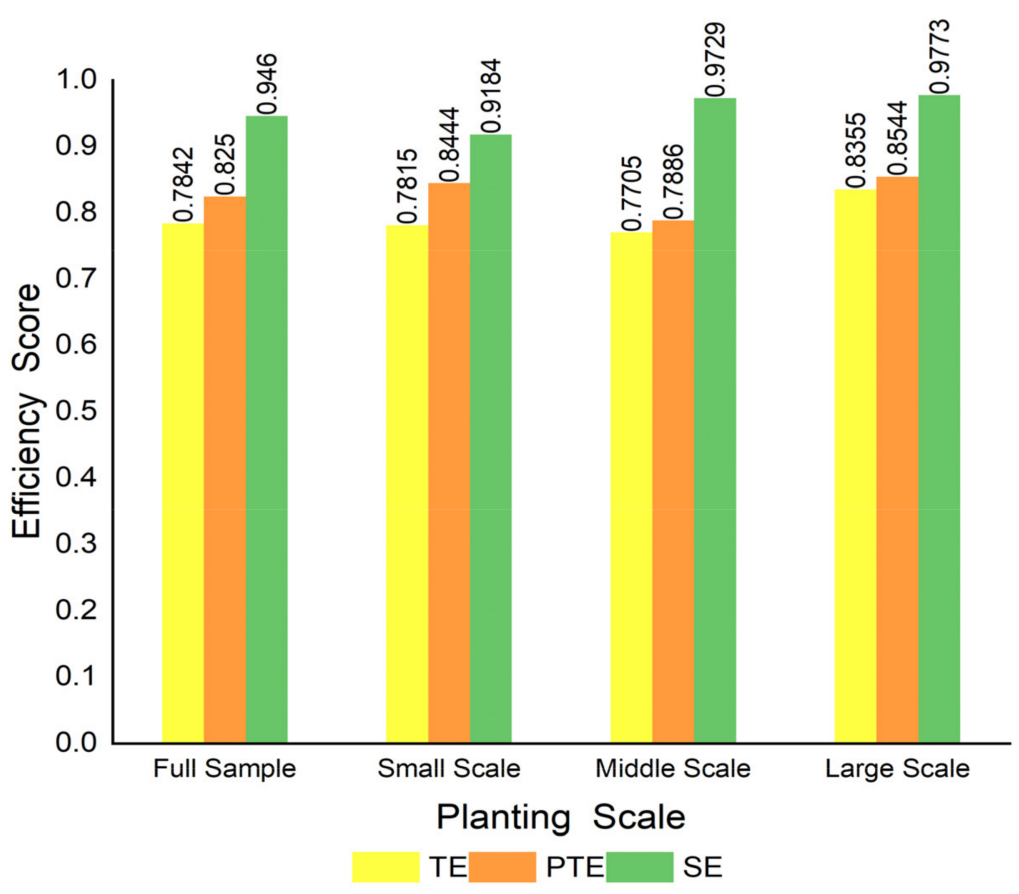

Figure 4. Technical, pure technical, and scale efficiency based on different planting scales.

\subsection{Factors Affecting Production Efficiency}

Based on actual investigations at the household level, and taking into account the technical characteristics of seed-producing corn farming in Zhangye City, we focused on examining the quality (including human capital and management practices) of the laborers who are involved in the production of seed corn. We selected control variables based on the basic economic status of rural households, the level of production technology application, and the input of production factors. Taking the farmer's production efficiency measured by the DEA method as the explained variable, we conducted a tobit regression model to analyze the factors influencing the farmers' production efficiency at different planting scales. The specific indicators are shown in Table 4. As shown in Figure 5, the relationship between TE and each influencing factor was drawn separately by using Stata software, which enables a preliminary analysis of the expected impact. The average duration of technical training for labor, average education time of labor force, the planting income per unit area, and the productive service expenditure per unit area may be positively correlated with 
agricultural production efficiency. The average age of farmers and the amount of pesticides and fertilizers per unit area may be negatively correlated with agricultural production efficiency. The time ratio of off-farm activities to agricultural production activities may have opposite effects on agricultural production efficiency with different planting scales.
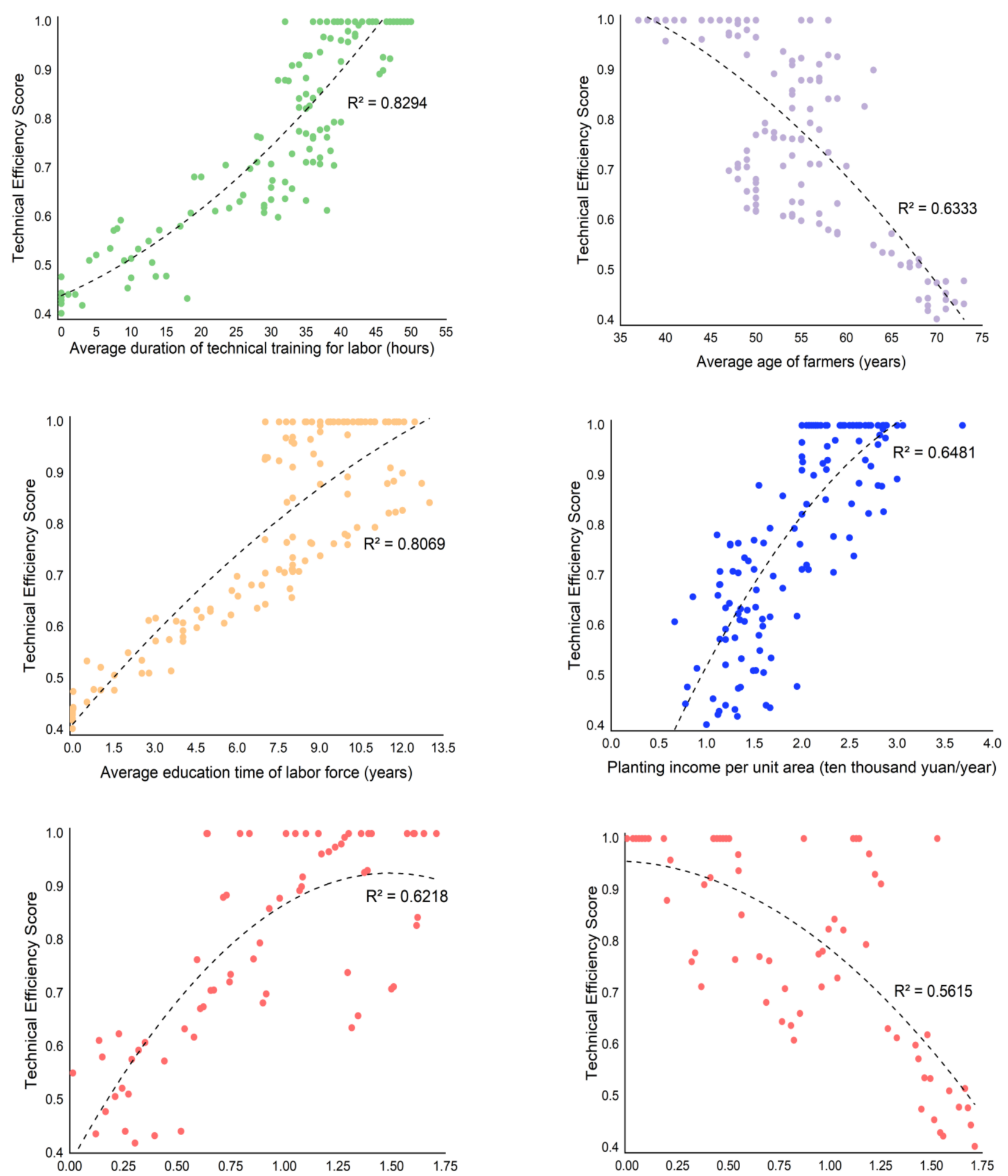

Duration of off-farm business activities/Duration of agricultural activities (small-scale farmers)

Duration of off-farm business activities/Duration of agricultural activities (medium-scale and large-scale farmers)

Figure 5. Cont. 


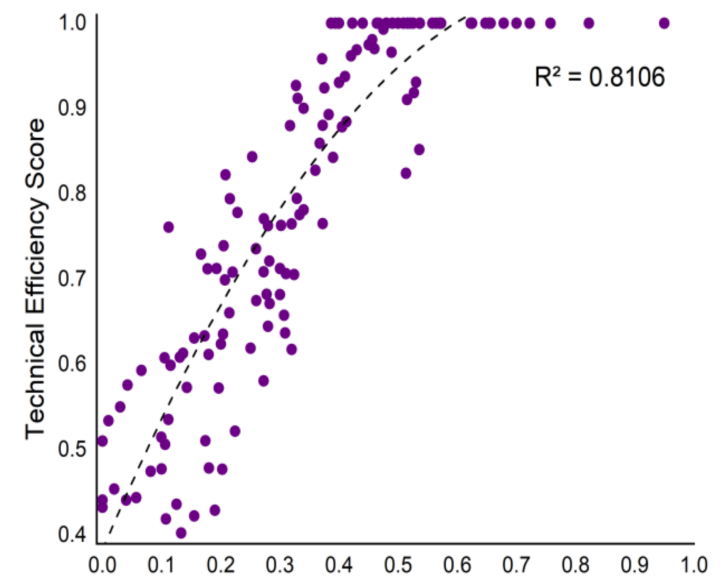

Productive service expenditure per unit area (thousand yuan/year)

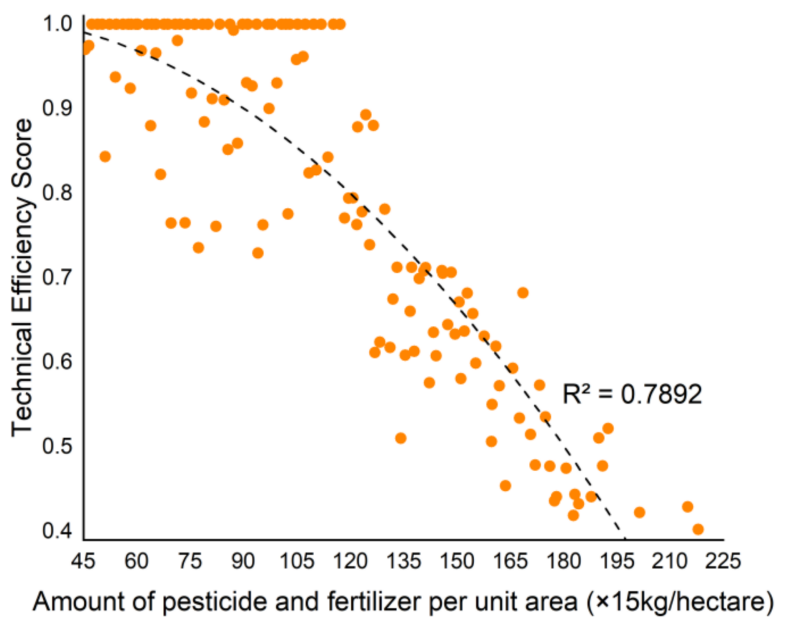

Figure 5. The relationship between farmers' production efficiency and influencing factors.

Table 4. Statistical description of factors that influence efficiency and their expected signs.

\begin{tabular}{|c|c|c|c|c|c|c|}
\hline Variable & Description & Mean & Max & Min & $\begin{array}{l}\text { Standard } \\
\text { Deviation }\end{array}$ & $\begin{array}{l}\text { Expected } \\
\text { Impact }\end{array}$ \\
\hline $\mathrm{X} 1$ & $\begin{array}{l}\text { Average duration of } \\
\text { technical training for } \\
\text { labor (hours) }\end{array}$ & 31.04 & 50.00 & 0.00 & 13.56 & + \\
\hline $\mathrm{X} 2$ & $\begin{array}{l}\text { Average age of farmers } \\
\text { (years) }\end{array}$ & 53.68 & 73.00 & 37.00 & 8.78 & - \\
\hline $\mathrm{X} 3$ & $\begin{array}{l}\text { Average education time } \\
\text { of labor force (years) }\end{array}$ & 7.33 & 13.01 & 0.00 & 3.61 & + \\
\hline $\mathrm{X} 4$ & $\begin{array}{l}\text { Planting income per unit } \\
\text { area (ten thousand } \\
\text { yuan/year) }\end{array}$ & 0.19 & 0.37 & 0.07 & 0.06 & + \\
\hline$X 5$ & $\begin{array}{l}\text { Time ratio of off-farm } \\
\text { activities to agricultural } \\
\text { production activities }\end{array}$ & 0.88 & 1.71 & 0.00 & 0.49 & $+/-$ \\
\hline $\mathrm{X} 6$ & $\begin{array}{l}\text { Productive service } \\
\text { expenditure per unit area } \\
\text { (thousand yuan/year) }\end{array}$ & 0.34 & 0.95 & 0.00 & 0.19 & + \\
\hline$X 7$ & $\begin{array}{l}\text { Amount of pesticide and } \\
\text { fertilizer per unit area } \\
\quad(\times 15 \mathrm{~kg} / \text { hectare })\end{array}$ & 115.22 & 218.00 & 40.50 & 43.50 & - \\
\hline
\end{tabular}

To explore whether various influencing factors have differential impacts on the production efficiency of farmers at different planting scales, we conducted a tobit regression for small-, medium-, and large-scale farmers. In practical applications, the interpretation of the tobit regression coefficient is different from the regression coefficient of the general linear model. The regression coefficient obtained after running the tobit command with the stata software does not represent the marginal effect of the explanatory variable on the explained variable, so further calculations are made. The marginal effects of the factors influencing the production efficiency of farmers are shown for the full sample and by farmland scale categories in Table 5. Differences exist in marginal impacts for different scales of farmland. In the following section, we offer a detailed discussion on the effects of different influencing factors on the agricultural production efficiency of farmers of different scales. 
Table 5. Marginal effects of factors affecting the production efficiency based on different farm scales.

\begin{tabular}{|c|c|c|c|c|c|c|c|c|}
\hline \multirow[b]{2}{*}{ Variable } & \multicolumn{2}{|c|}{ Full Sample } & \multicolumn{2}{|c|}{ Small Scale } & \multicolumn{2}{|c|}{ Medium Scale } & \multicolumn{2}{|c|}{ Large Scale } \\
\hline & $\begin{array}{c}\text { Marginal } \\
\text { Effect }\end{array}$ & Z Score & $\begin{array}{c}\text { Marginal } \\
\text { Effect }\end{array}$ & Z Score & $\begin{array}{c}\text { Marginal } \\
\text { Effect }\end{array}$ & Z Score & $\begin{array}{c}\text { Marginal } \\
\text { Effect }\end{array}$ & Z Score \\
\hline $\mathrm{X} 1$ & 0.0944 & $4.27^{* * *}$ & 0.0644 & $3.93^{* * *}$ & 0.0828 & $4.69 * * *$ & 0.1015 & $4.95^{* * *}$ \\
\hline $\mathrm{X} 2$ & -0.0562 & $-1.76^{*}$ & -0.0686 & $-2.30^{* *}$ & -0.0335 & $-1.69 *$ & -0.0521 & $-2.47^{* *}$ \\
\hline $\mathrm{X} 3$ & 0.1184 & $2.32 * *$ & 0.0985 & 1.93 * & 0.0672 & $2.43^{* *}$ & 0.1189 & $2.35^{* *}$ \\
\hline$X 4$ & 0.0486 & $1.68 *$ & 0.0325 & 1.91 * & 0.0582 & $2.56^{* *}$ & 0.0603 & $2.47^{* *}$ \\
\hline $\mathrm{X} 5$ & -0.0652 & $-2.23^{* *}$ & 0.0527 & $2.65^{* * *}$ & -0.0519 & $-2.14^{* *}$ & -0.0786 & -1.83 * \\
\hline X6 & 0.1089 & $2.18^{* *}$ & 0.0973 & $2.37^{* *}$ & 0.1195 & $2.28^{* *}$ & 0.1024 & $1.69^{*}$ \\
\hline $\mathrm{X} 7$ & -0.0725 & $-2.56^{* *}$ & -0.0753 & $-3.57^{* * *}$ & -0.0614 & $-2.49 * *$ & -0.0512 & -1.86 * \\
\hline
\end{tabular}

Note: The symbols ${ }^{*},{ }^{* *}$, and ${ }^{* * *}$ indicate statistical significance at the $10 \%, 5 \%$, and $1 \%$ levels, respectively.

\section{Discussion}

The average comprehensive technical efficiency score of the entire sample of farmers is $0.7842(<1)$, which is below the relatively effective level. There is room to improve efficiency by $21.58 \%$, particularly in relation to average pure technical efficiency, which, at 0.8250 , is less than the average scale efficiency $(0.9460)$. This shows that the main reasons for the failure to achieve relatively effective production efficiency are the insufficient application of agricultural production technology and the lack of production management. As shown in Figure 4, based on the comparison of different planting scales, the average comprehensive technical efficiency is highest for large-scale farmers (0.8355), followed by small-scale farmers (0.7815), with that of medium-scale farmers (0.7705) being the lowest. This is contrary to the belief that small-scale farmland management is more productive than large-scale farmland management in previous studies [56-58]. The field research revealed that due to the loss of young laborers to the larger cities and urban areas, the remaining small-scale farmers are mostly middle-aged or elderly. Such laborers have limited labor capacity, which contrasts with the traditional belief that small-scale farmers take greater care of crops and are more efficient with inputs. The higher age and lower education of the labor force left behind when younger laborers shift away inevitably affect agricultural production efficiency. Regardless of the size of farms, the scale efficiency value is significantly higher than the pure technical efficiency value, indicating that further improvement of comprehensive technical efficiency depends on the effective application of planting technology. In addition, the scale efficiency value increases with the scale of farmland, indicating that a moderate expansion of the household production size would be beneficial to improving scale efficiency.

For the full sample of farmers, average duration of technical training for labor (X1) has a positive marginal effect on production efficiency. Owing to the farm conditions in the arid area of northwest China - namely sufficient sunlight, heat, and scarce water resourcestwo modes of agriculture, irrigated agriculture and rain-fed agriculture, coexist. Therefore, assisting farmers to learn dry farming and water-saving techniques, including water and fertilizer integration under film drip irrigation and other practical techniques, and to understand pest and disease prevention and control technology, will assist in significantly improving the efficiency and level of agricultural production $[59,60]$. According to our investigations and studies, in recent years, villages and towns in Zhangye have used methods such as on-site guidance on production technology problems, centralized training in towns, demonstration of new technologies, and household training to provide practical technical training to farmers. These methods have significantly improved the level of agricultural production efficiency. Agricultural production technology training has had a more significant marginal effect on medium- and large-scale farmers than on small-scale farmers. Our survey indicated that small-scale farmers are more inclined to reject new knowledge and new technologies. As noted, most small-scale farmers are older laborers, who lack the energy or willingness to learn or accept new knowledge and technologies. Conversely, because smaller-scale farmers mostly participate in seasonally-based work 
activities, learning new technologies may prevent them from performing off-farm work during non-harvest seasons to obtain higher non-agricultural income. For small-scale farmers, this is natural and rational behavior. However, for society as a whole, it is not conducive to the sustainable development of agriculture.

The average age of farmers (X2) has a significantly negative effect on the production efficiency of farmers. In recent years, with the rapid development of the urban economy, the income gap between urban and rural areas has further widened. Young and middleaged rural laborers who are educated and possess business-oriented technical skills have abandoned rural areas and agricultural production in favor of working in urban areas, leading to the emergence of a large number of "hollow villages". With the loss of the young workforce and the aging of remaining farmers, inefficient use of agricultural land resources and underinvestment in field management have become more serious. In addition, it indirectly leads to an increase in agricultural production costs and restricts the uptake of agricultural technology, which limits the improvement of agricultural production efficiency. Our results indicate that the increasingly aging labor force reduces the relative production efficiency of small-scale farmers more than in the case for medium- and large-scale farms. This verifies that the aging of the labor force leads to the lower relative production efficiency of small-scale farmers, and is also consistent with the actual situation indicated by the survey.

The average education time of labor force $(\mathrm{X} 3)$ has a positive effect on the production efficiency of farmers. In the era of the knowledge economy, the determinant of productivity has shifted from the quantity to the quality of human capital [61]. The quality of labor is one of the most important factors influencing the development of rural human resources. In the context of agricultural modernization, farmers must achieve higher production efficiency and require a deeper grasp of the laws of inputs and output. The higher the education level of the workers, the greater is their acceptance and application of agricultural technologies, including formula fertilization, soil analysis, and new breeding technologies, which will be beneficial to agricultural production.

The income from planting per unit area (X4) has a statistically significant positive marginal effect at the $10 \%$ level on the production efficiency of farmers. In addition, we found that the larger the scale of operation, the more significant is this marginal positive effect. Higher farming incomes encourage farmers to improve the condition of their production materials. The survey indicates that the income of large-scale growers is invested in agricultural machinery to aid large-scale farmland management. Greater mechanization has significantly improved agricultural operations, which is conducive to increasing labor productivity and the efficiency of agricultural production.

From the neoclassical perspective of economies of scale, farmers who combine seasonal farming and working off-farm to earn sufficient income is not conducive to improving the agricultural structure and optimizing land use. It entrenches small-scale agricultural operations, hinders the formation of economies of scale, and inhibits efficient agricultural production [57]. In Table 5, the marginal effect of time ratio of off-farm activities to agricultural production activities (X5) on medium-scale and large-scale farmers is negative, which validates this theory. Conversely, the empirical results show that the production efficiency of small-scale farmers is positively promoted by non-agricultural activities. The field surveys revealed that for many small-scale farmers, the income from off-farm work exceeds their agricultural production income. Therefore, farming income is no longer their main source of income, and its share of their total income has continued to decline in recent years. Most small farmers cannot rely on their agricultural income to maintain their standard of living. Instead, they earn additional off-farm income through part-time work and use this to "subsidize" their agricultural production, e.g., by using it to purchase production materials and maintain their agricultural operations. This provides an empirical explanation for why the marginal effect of migrant work or business income has a positive effective on the production efficiency of small-scale farmers. 
Expenditures for productive services include repair costs and fees for employed machinery operations, technical consulting, and employed laborers. The empirical results show that the production service expenditure per unit area (X6) has a positive marginal effect on farmers of any size, although the effect is more significant for medium- and large-scale farmers. The survey results show that compared with the family operations mode of small-scale farmers, large-scale farms have larger operations with more labor and mechanical power, which is more conducive to improving production efficiency.

The agricultural production activities in the Hexi Corridor oasis agricultural area are characterized by high input levels of chemical fertilizers and pesticides but an infrequent utilization rate [62]. Excessive application of chemical fertilizers and pesticides is not only detrimental to the improvement of agricultural productivity, but also potentially poses a serious environmental threat. The marginal effect of the amount of pesticides and fertilizers per unit area (X7) on the production efficiency of farmers is significantly negative at the $5 \%$ significance level of the full sample. Compared with medium- and large-scale farmers, the production efficiency of small-scale farmers is more obviously inhibited by the amount of fertilizer applied. The survey results showed that the small-scale farm labor force remaining in the area is aging, the scale of operations is small, and the level of mechanization is low. The application of pesticides and fertilizers on these small-scale farms is reliant on the young and middle-aged laborers who return to the countryside to assist on the farms for short periods of time. However, as they would prefer to spend their time on higher-yielding urban activities, they often use the "one bombardment" fertilization method, which involves applying large amounts once only. This extensive management method not only leads to the decline of crop resistance to pests and diseases, but it also leads to the loss of soil nutrients. In addition, it creates environmental problems such as air and water pollution, which reduce the efficiency of agricultural production.

\section{Conclusions}

The research object of this study is the seed-producing corn growers in Zhangye City. We supplemented special survey data using the national input-output survey, and used the DEA method to measure agricultural production efficiency, as well as a tobit regression to calculate the marginal effect of factors affecting production efficiency. Based on the analysis of farms of different operating scales, we obtained the following conclusions. (1) There is room to improve the comprehensive technical efficiency by $21.58 \%$ of seed corn production. The failure to achieve efficient production is largely caused by the insufficient application of agricultural production technology and the lack of production management. Additionally, the production efficiency of large-scale farmers is higher than that of smaller-scale farmers. (2) Duration of technical training, education time of laborers, planting income, and productive expenditure are significantly positively correlated with production efficiency. Average age of farmers and the amount of pesticide and fertilizer use are significantly negatively correlated with production efficiency. Moreover, as the scale of farmland varies, the marginal impacts vary. Off-farm activities can improve the production efficiency of small-scale farmers, but inhibit the production efficiency of medium- and large-scale farmers. The results show that the small scale of cultivated land has become a restrictive factor limiting the returns of factor inputs and human capital investment. The expansion of production scale is an effective means to improve the efficiency of agricultural production.

Combining the results of the field investigations and research, we found that appropriately expanding the scale of household farmland and optimizing human resources are effective ways to improve agricultural production efficiency in arid oasis areas. Efforts should focus on the following actions. (1) Encouraging willing growers to moderately expand the scale of their agricultural operations through land transfers and other methods. Compared with family workshop-style and small-scale farming operations, large-scale and intensive farming households have greater economies of scale and higher levels of mechanization. Gradually expanding the scale of farmland through appropriate policies 
will assist in increasing production efficiency. (2) Increasing the promotion of agricultural production technology and the scope of agricultural production technology training [63]. For agriculture in arid oasis areas, reforms to improve efficiency and promote sustainable development should include the construction of farmland water conservation facilities, adjusting the structure of agricultural production, increasing the application of organic fertilizers, implementing bio-fertilizer soil technology, adopting drought-tolerant crop varieties, and developing water-saving agriculture production methods. (3) Formulating special support policies for young and middle-aged laborers, increasing farmers' incomes through multiple channels [64], and attracting knowledgeable and skilled youth to return to the countryside to work in agriculture so that they have greater incentives to choose agricultural production as a career. These methods can alleviate the loss of rural human resources and the aging of the remaining labor force, and promote the improvement of agricultural production efficiency by improving the quality of human capital.

The limitations of this article are that short-term studies are difficult to measure for many variables that may change in the long-term. The long-term effects of prices, policies and other factors on agricultural productivity need to be further explored. The results may be biased due to the cultural background of the respondents. In future studies, we may include the respondents' value perception and psychological factors as measurement indicators, and use a larger sample size to reduce sample selection bias.

Author Contributions: Conceptualization, F.Z., Y.W. and P.W.; data curation, Y.W., P.W. and X.S.; formal analysis, F.Z., Y.W. and X.L.; investigation, Y.W., P.W. and X.S.; methodology, P.W., Y.W. and X.L.; resources, F.Z., Y.W., X.L. and P.W.; software, Y.W. and X.L.; supervision, F.Z. and X.S.; validation, F.Z., Y.W. and P.W.; visualization, F.Z., Y.W. and X.L.; writing-original draft, F.Z., Y.W. and P.W; writing-review and editing, F.Z., Y.W., X.L., P.W. and X.S. All authors have read and agreed to the published version of the manuscript.

Funding: This research was supported by the National Key R\&D Program of China (grant nos. 2018YFD1100102, 2018YFC1509007), the National Natural Science Foundation of China (grant no. 41801208), and the Strategic Priority Research Program of the Chinese Academy of Sciences (grant no. XDA20100104).

Institutional Review Board Statement: Not applicable.

Informed Consent Statement: Not applicable.

Data Availability Statement: Relevant data can be obtained by contacting the corresponding author with reasonable reasons.

Conflicts of Interest: The authors declare no conflict of interest.

\section{References}

1. Feng, J.; Zhao, L.; Zhang, Y.; Sun, L.; Yu, X.; Yu, Y. Can climate change influence agricultural GTFP in arid and semi-arid regions of Northwest China? J. Arid. Land 2020, 12, 837-853. [CrossRef]

2. Dagar, V.; Khan, M.K.; Alvarado, R.; Usman, M.; Zakari, A.; Rehman, A.; Murshed, M.; Tillaguango, B. Variations in technical efficiency of farmers with distinct land size across agro-climatic zones: Evidence from India. J. Clean. Prod. 2021, $315,128109$. [CrossRef]

3. Gołaś, M.; Sulewski, P.; Wass, A.; Kłoczko-Gajewska, A.; Pogodzińska, K. On the Way to Sustainable Agriculture-Eco-Efficiency of Polish Commercial Farms. Agriculture 2020, 10, 438. [CrossRef]

4. Li, C.; Shi, Y.; Khan, S.U.; Zhao, M. Research on the impact of agricultural green production on farmers' technical efficiency: Evidence from China. Environ. Sci. Pollut. Res. 2021, 1-17. [CrossRef] [PubMed]

5. Liao, J.; Yu, C.; Feng, Z.; Zhao, H.; Wu, K.; Ma, X. Spatial differentiation characteristics and driving factors of agricultural eco-efficiency in Chinese provinces from the perspective of ecosystem services. J. Clean. Prod. 2021, 288, 125466. [CrossRef]

6. Ma, L.; Long, H.; Tang, L.; Tu, S.; Zhang, Y.; Qu, Y. Analysis of the spatial variations of determinants of agricultural production efficiency in China. Comput. Electron. Agric. 2021, 180, 105890. [CrossRef]

7. Agovino, M.; Cerciello, M.; Gatto, A. Policy efficiency in the field of food sustainability. The adjusted food agriculture and nutrition index. J. Environ. Manag. 2018, 218, 220-233. [CrossRef]

8. Capalbo, S.M.; Antle, J.M. Agricultural Productivity: Measurement and Explanation, 1st ed.; Taylor and Francis: London, UK, 2015; pp. 15-17. [CrossRef] 
9. Yan, J.; Chen, C.; Hu, B. Farm size and production efficiency in Chinese agriculture: Output and profit. China Agric. Econ. Rev. 2019, 11, 20-38. [CrossRef]

10. Nandy, A.; Singh, P.K.; Singh, A.K. Systematic Review and Meta- regression Analysis of Technical Efficiency of Agricultural Production Systems. Glob. Bus. Rev. 2021, 22, 396-421. [CrossRef]

11. Xia, S. Research on the Impact of Capital Deepening and Endowment Structure on Agricultural Production Efficiency. Ph.D. Thesis, Zhejiang University, Hangzhou, China, 2018. [CrossRef]

12. $\mathrm{Wu}, \mathrm{F}$. The application of parametric and nonparametric frontier methods in the measurement of productivity efficiency. J. Appl. Stat. 2005, 5, 50-55. [CrossRef]

13. Umar, H.; Onukand, E.; Adigwe, F. Stochastic production function and technical efficiency of maize farms in southern agricultural zone of Nasarawa State Nigeria. J. Agric. Food Sci. 2018, 15, 34. [CrossRef]

14. Huang, W.; Xu, L.; Guo, Y. Analysis on Technical Efficiency and Influencing Factors of Agricultural Production in China-Based on the Stochastic Frontier Analysis model. E3S Web Conf. 2021, 235, 34-42. [CrossRef]

15. Singvejsakul, J.; Intapan, C.; Chaiboonsri, C.; Permsiri, R. Bayesian Stochastic Frontier Analysis of Agricultural productivity efficiency in CLMV. J. Phys. Conf. Ser. 2021, 1936, 012006. [CrossRef]

16. Salame, E.J. Sources of Agricultural Productivity Differences between Israel, Jordan, Lebanon and Syria using DEA. Int. J. Prod. Manag. Assess. Technol. 2014, 2, 47-61. [CrossRef]

17. Ullah, A.; Perret, S.R.; Gheewala, S.H.; Soni, P. Eco-efficiency of cotton-cropping systems in Pakistan: An integrated approach of life cycle assessment and data envelopment analysis. J. Clean. Prod. 2016, 134, 623-632. [CrossRef]

18. Bagchi, M.; Rahman, S.; Shunbo, Y. Growth in Agricultural Productivity and Its Components in Bangladeshi Regions (1987-2009): An Application of Bootstrapped Data Envelopment Analysis (DEA). Economies 2019, 7, 37. [CrossRef]

19. Theodoridis, A.; Ragkos, A.; Roustemis, D.; Galanopoulos, K.; Abas, Z.; Sinapis, E. Assessing technical efficiency of Chios sheep farms with data envelopment analysis. Small Rumin. Res. 2012, 107, 85-91. [CrossRef]

20. Liu, Z.; Yin, Y.; Pan, J.; Ying, H.; Lu, D.; Batchelor, W.; Ma, W.; Cui, Z. Yield Gap Analysis of County Level Irrigated Wheat in Hebei Province, China. Agron. J. 2019, 111, 2245-2254. [CrossRef]

21. Abdul-Rahaman, A.; Issahaku, G.; Zereyesus, Y.A. Improved rice variety adoption and farm production efficiency: Accounting for unobservable selection bias and technology gaps among smallholder farmers in Ghana. Technol. Soc. 2021, 64, 101471. [CrossRef]

22. Adhikari, C.B.; Bjorndal, T. Analyses of technical efficiency using SDF and DEA models: Evidence from Nepalese agriculture. Appl. Econ. 2012, 44, 3297-3308. [CrossRef]

23. Godoy-Durán, Á.; Gómez, E.G.; Mesa, J.C.P.; Piedra-Muñoz, L. Assessing eco-efficiency and the determinants of horticultural family-farming in southeast Spain. J. Environ. Manag. 2017, 204, 594-604. [CrossRef]

24. Stępień, S.; Czyżewski, B.; Sapa, A.; Borychowski, M.; Poczta, W.; Poczta-Wajda, A. Eco-efficiency of small-scale farming in Poland and its institutional drivers. J. Clean. Prod. 2021, 279, 123721. [CrossRef]

25. Baba, S.H.; Khan, O.F.; Kawoosa, T. Human Resource Development, Agricultural Productivity and Household Income in Rural Jammu and Kashmir. Int. J. Educ. Manag. Stud. 2018, 8, 315-322.

26. Czyżewski, B.; Sapa, A.; Kułyk, P. Human Capital and Eco-Contractual Governance in Small Farms in Poland: Simultaneous Confirmatory Factor Analysis with Ordinal Variables. Agriculture 2021, 11, 46. [CrossRef]

27. Yin, Y.; Ying, H.; Xue, Y.; Zheng, H.; Zhang, Q.; Cui, Z. Calculating socially optimal nitrogen (N) fertilization rates for sustainable $\mathrm{N}$ management in China. Sci. Total Environ. 2019, 688, 1162-1171. [CrossRef] [PubMed]

28. Xie, K.; Guo, J.; Ward, K.; Luo, G.; Shen, Q.; Guo, S. The Potential for Improving Rice Yield and Nitrogen Use Efficiency in Smallholder Farmers: A Case Study of Jiangsu, China. Agronomy 2020, 10, 419. [CrossRef]

29. Pangapanga-Phiri, I.; Mungatana, E.D. Adoption of climate-smart agricultural practices and their influence on the technical efficiency of maize production under extreme weather events. Int. J. Disaster Risk Reduct. 2021, 61, 102322. [CrossRef]

30. Manjunatha, A.; Anik, A.R.; Speelman, S.; Nuppenau, E. Impact of land fragmentation, farm size, land ownership and crop diversity on profit and efficiency of irrigated farms in India. Land Use Policy 2013, 31, 397-405. [CrossRef]

31. Zeng, L.; Li, X.; Ruiz-Menjivar, J. The effect of crop diversity on agricultural eco-efficiency in China: A blessing or a curse? J. Clean Prod. 2020, 276, 124243. [CrossRef]

32. Asseng, S.; Guarin, J.R.; Raman, M.; Monje, O.; Kiss, G.; Despommier, D.D.; Meggers, F.M.; Gauthier, P.P.G. Wheat yield potential in controlled-environment vertical farms. Proc. Natl. Acad. Sci. USA 2020, 117, 19131-19135. [CrossRef]

33. Babu, S.; Mohapatra, K.; Das, A.; Yadav, G.S.; Tahasildar, M.; Singh, R.; Panwar, A.; Yadav, V.; Chandra, P. Designing energyefficient, economically sustainable and environmentally safe cropping system for the rainfed maize-fallow land of the Eastern Himalayas. Sci. Total Environ. 2020, 722, 137874. [CrossRef]

34. Pham, H.-G.; Chuah, S.-H.; Feeny, S. Factors affecting the adoption of sustainable agricultural practices: Findings from panel data for Vietnam. Ecol. Econ. 2021, 184, 107000. [CrossRef]

35. Rusciano, V.; Civero, G.; Scarpato, D. Urban gardens and environmental sustainability: An empirical research of Campania region. Qual. Access Success 2017, 18, 376-381.

36. Berre, D.; Corbeels, M.; Rusinamhodzi, L.; Mutenje, M.; Thierfelder, C.; Lopez-Ridaura, S. Thinking beyond agronomic yield gap: Smallholder farm efficiency under contrasted livelihood strategies in Malawi. Field Crop. Res. 2017, 214, 113-122. [CrossRef]

37. Charnes, A.; Cooper, W.W.; Rhodes, E. Measuring the efficiency of decision making units. Eur. J. Oper. Res. 1978, 2, 429-444. [CrossRef] 
38. Seiford, L.M.; Thrall, R.M. Recent developments in DEA: The mathematical programming approach to frontier analysis. J. Econom. 1990, 46, 7-38.

39. Banker, R.D.; Charnes, A.; Cooper, W.W. Some Models for Estimating Technical and Scale Inefficiencies in Data Envelopment Analysis. Manag. Sci. 1984, 30, 1078-1092. [CrossRef]

40. Khezrimotlagh, D.; Chen, Y. Decision Making and Performance Evaluation Using Data Envelopment Analysis, 1st ed.; Springer: Cham, Switzerland, 2018. [CrossRef]

41. Cook, W.D.; Seiford, L.M. Data envelopment analysis (DEA)-Thirty years on. Eur. J. Oper. Res. 2009, 192, 1-17. [CrossRef]

42. Tobin, J. Estimation of relationships for limited dependent variables. Econometric 1958, 26, 24-36. [CrossRef]

43. Moffitt, R.B.; McDonald, J. The Uses of Tobit Analysis. Rev. Econ. Stat. 1980, 62, 318-321.

44. Heckman, J.J. Sample Selection Bias as a Specification Error. Econometrica 1979, 47, 153. [CrossRef]

45. Agriculture and Rural Bureau of Zhangye City. Analysis on the Development Situation of Corn Seed Production Industry in Zhangye City. Available online: http:/ / www.zhangye.gov.cn/nyj/ (accessed on 16 March 2021).

46. Zhong, F.; Jiang, D.; Zhao, Q.; Guo, A.; Ullah, A.; Yang, X.; Cheng, Q.; Zhang, Y.; Ding, X. Eco-efficiency of oasis seed maize production in an arid region, Northwest China. J. Clean. Prod. 2020, 268, 122220. [CrossRef]

47. Zhong, F.; Yang, X.; Guo, A. Agricultural Eco-Economic Efficiency of Oasis in Arid Area Based on the Combination of LCA and DEA Method-A Case Study of Seed Maize in Zhangye City. Ecol. Econ. 2017, 33, 122-127.

48. Jiang, D.; Zhong, F.; Guo, A. Study on the efficiency of maize production in the oasis field in the arid zone: A case study of growers in Zhangye City. Arid. Land Resour. Environ. 2017, 31, 167-171. [CrossRef]

49. Yang, X.; Zhong, F.; Guo, A. Evaluation of the difference in production efficiency of farmers in oasis and improvement strategies: A case study of maize production in Zhangye City. Arid. Land Geogr. 2017, 40, 913-919. [CrossRef]

50. Balezentis, T.; Krisciukaitiene, I. Family Farm Efficiency Across Farming Typesin Lithuania And its Managerial Implications-Data Envelopment Analysis; Lithuanian Institute of Agrarian Economics: Vilnius, Lithuania, 2012; p. 30.

51. Luo, X.-S.; Muleta, D.; Hu, Z.; Tang, H.; Zhao, Z.; Shen, S.; Lee, B.-L. Inclusive development and agricultural adaptation to climate change. Curr. Opin. Environ. Sustain. 2017, 24, 78-83. [CrossRef]

52. Delvaux, P.A.G.; Riesgo, L.; Paloma, S.G.Y. Are small farms more performant than larger ones in developing countries? Sci. Adv. 2020, 6, eabb8235. [CrossRef]

53. Adeniyi, D.A.; Dinbabo, M.F. Efficiency, food security and differentiation in small-scale irrigation agriculture: Evidence from North West Nigeria. Cogent Soc. Sci. 2020, 6, 1749508. [CrossRef]

54. Polcyn, J. Eco-Efficiency and Human Capital Efficiency: Example of Small- and Medium-Sized Family Farms in Selected European Countries. Sustainability 2021, 13, 6846. [CrossRef]

55. Maican, S.; Muntean, A.; Paștiu, C.; Stępień, S.; Polcyn, J.; Dobra, I.; Dârja, M.; Moisă, C. Motivational Factors, Job Satisfaction, and Economic Performance in Romanian Small Farms. Sustainability 2021, 13, 5832. [CrossRef]

56. Berti, G.; Mulligan, C. Competitiveness of Small Farms and Innovative Food Supply Chains: The Role of Food Hubs in Creating Sustainable Regional and Local Food Systems. Sustainability 2016, 8, 616. [CrossRef]

57. Gao, X.; Zhang, A. The relationship between agricultural land transfer, the degree of farmers' concurrent work and pro-duction efficiency. CJPRE 2017, 27, 121-128.

58. Smith, A.; Snapp, S.; Chikowo, R.; Thorne, P.; Bekunda, M.; Glover, J. Measuring sustainable intensification in smallholder agroecosystems: A review. Glob. Food Secur. 2017, 12, 127-138. [CrossRef]

59. He, D.-C.; Ma, Y.-L.; Li, Z.-Z.; Zhong, C.-S.; Cheng, Z.-B.; Zhan, J. Crop Rotation Enhances Agricultural Sustainability: From an Empirical Evaluation of Eco-Economic Benefits in Rice Production. Agriculture 2021, 11, 91. [CrossRef]

60. Raimondo, M.; Caracciolo, F.; Nazzaro, C.; Marotta, G. Organic Farming Increases the Technical Efficiency of Olive Farms in Italy. Agriculture 2021, 11, 209. [CrossRef]

61. Baležentis, T.; Li, T.; Chen, X. Has agricultural labor restructuring improved agricultural labor productivity in China? A decomposition approach. Socio-Econ. Plan. Sci. 2021, 76, 100967. [CrossRef]

62. Chen, M.; Ma, L.; Che, X.; Dou, H. Identification of Transformation Stages and Evolution of Agricultural Development Types Based on Total Factor Productivity Analysis: A Case Study of Gansu Province, China. Agriculture 2020, 10, 363. [CrossRef]

63. Keating, B.A.; Carberry, P.S.; Bindraban, P.S.; Asseng, S.; Meinke, H.; Dixon, J. Eco-efficient Agriculture: Concepts, Challenges, and Opportunities. Crop. Sci. 2010, 50, S-109-S-119. [CrossRef]

64. Garrone, M.; Emmers, D.; Lee, H.; Olper, A.; Swinnen, J. Subsidies and agricultural productivity in the EU. Agric. Econ. 2019, 50, 803-817. [CrossRef] 